\title{
Before I kick the bucket, I want to say thank you
}

\section{John D Townsend}

Patients don't always get a chance to tell people when and how care is superb. John D Townsend explains why he needs to say it now. For more information about the series, contact Rosamund Snow, patient editor, rsnow@bmj.com.

My GP is absolutely fantastic. Three years ago I sat in front of her describing my symptoms. She listened carefully, examined me, and then she asked:

"What do you think it is?"

I knew I'd lost a lot of weight, lost my appetite, and had even been passing blood. I'd had to put extra holes in my belt to keep my trousers up. There wasn't any point in beating about the bush, so I told her: "I think it's bowel cancer."

She looked taken aback. I don't think she had expected me to be quite that blunt, or quite that cheerful. But I'd already decided that if this was what nature was going to throw at me I'd just deal with it. As she referred me for further investigations, she said she'd never seen anyone face the idea of an operation for cancer with such a positive attitude.

The local hospital sent me a thick booklet with information, laxatives, the lot, all within two days. This is in a system that politicians and the press tell us, every day, isn't working; a system that is supposed to be slow. I don't understand why people moan about the NHS - I have never had a problem with it.

When they did the investigations for bowel cancer they found that I also had cancer of the oesophagus. They asked me if I had pain or difficulty swallowing, but I told them I had no symptoms for that cancer at all. Because the bowel cancer was growing more slowly, they decided to remove the oesophageal cancer first, and 13 months later when my body had recovered I went back in for the bowel operation.

My oncologist is also wonderful. We understand each other, and we know how to talk to each other. On one visit to her clinic I arrived feeling awful. Bear in mind that I never used to go to the doctor and I was never unwell. In fact, until I had to retire because of the cancer I had worked for 27 years without a single day off sick. It was not typical for me to feel this bad. I told my oncologist that I was feeling rough; I wanted it all to be over. She listened to me describing how I felt and picked up the phone immediately: "I want a bed now. And I want a wheelchair here now." It was meant to be an outpatient appointment, but I was taken to hospital to be treated for double pneumonia. I didn't know I had pneumonia-I'd never had it before so how would
I know? But she knew right away, she took me seriously, and she acted fast. Again, people talk about the amount of time it takes to get anything done in the NHS, but that's not my experience.

In the middle of February this year my oncologist sent for me. "The cancer we took out of your oesophagus has come back" she told me. "We can't do any more for you because your body's not strong enough for chemo."

"Right," I said. "How long have I got, weeks or months?" "Months."

(Look, I'm practical, I need to know where I'm going with this.)

"So this time next year I won't be here?"

"Yes. That's right."

Sometimes it's worth being direct. There's no sitting on the fence, she calls a spade a spade. She wrote a letter to my GP, perhaps she rang her too, I don't know. I know she sent the letter because she sent me a copy so I could see that she had written: "John isn't afraid of dying."

Everybody's an individual. You have to talk to patients to understand their attitude. Ask questions and see what the replies are-that way you can see whether the person is the kind to get upset. Share that information, so others know how to communicate in the way the patient likes best.

I'm not going to fight it. I've already said to my wife that when I'm gone I don't want her putting in the paper that I lost a battle with cancer. I didn't lose any battle, because I'm not fighting this cancer. If I get worried about it, is that going to get rid of it? No. If I get stressed what good will that do? None.

Before I go I'm going to write to my member of parliament, to the prime minister, and to the management at my local hospital that all this bullshit about the NHS being rubbish is not true, not where I live. I've been treated so wonderfully that you wouldn't believe it.

I would like to acknowledge the help and support of staff and volunteers at Sobell House Hospice in Oxfordshire, UK.

Competing interests: I have read and understood BMJ policy on declaration of interests and declare the following interests: none.

Cite this as: BMJ 2015;351:h4706

๑ BMJ Publishing Group Ltd 2015 


\section{The bottom line}

- Don't have fixed ideas about how people will respond to being on a cancer ward. Some of us like you to be very direct; everyone's different

- You can help each other. If you have learnt the best way to talk to an individual patient take a moment to put it in the referral letter or a phone call. Pass that information on to other staff who are dealing with that person

- People don't thank healthcare staff enough. I want to say to all of you-GPs, surgeons, nurses of all kinds, right through to those who do the seemingly menial tasks (the people who got me fresh water or clean the wards)—-thank you. I can't fault you 